\title{
Assessment of Knowledge, Attitude, and Practices Regarding Self-medication for Acne Among Medical Students
}

Ahsan Tameez-ud-din ${ }^{1}$, Ifrah J. Malik ${ }^{1}$, Awais A. Bhatti ${ }^{1}$, Asim Tameez Ud Din ${ }^{1}$, Abdullah Sadiq ${ }^{2}$, Muhammad T. Khan ${ }^{1}$, Noman A. Chaudhary ${ }^{2}$, Daneyal Arshad ${ }^{1}$

1. Internal Medicine, Rawalpindi Medical University, Rawalpindi, PAK 2. Surgery, Rawalpindi Medical University, Rawalpindi, PAK

Corresponding author: Ahsan Tameez-ud-din, ahsantameezuddinmalik@gmail.com

\section{Abstract}

\section{Introduction}

Acne is one of the most common skin conditions worldwide. Self-medication for acne is a fairly common practice among medical students. The objective of our study was to identify the prevalence of selfmedication and to assess its knowledge, attitude, and practices among medical students.

\section{Materials and methods}

This descriptive cross-sectional study was conducted at Rawalpindi Medical University, Rawalpindi, Pakistan, from January 2019 to June 2019. Data were collected by using the convenient sampling technique. Students were asked to fill a semi-structured questionnaire. Students of all the medical years studying in our university were included in the study. Data were entered and analyzed using the Statistical Package for Social Sciences (SPSS) version 23.0 (IBM Corp., Armonk, US).

\section{Results}

Out of 349 students, 244 (69.9\%) suffered from acne and self-medication was practiced by 123 (50.4\%) acne sufferers. The practice of self-medication was significantly higher in students having acne lesions on the face (52.2\%). The most common source of information was reported to be acquaintances (55.8\%). Most of the students had knowledge of the dosage of drugs (46.3\%) and precautions for their use (41.5\%). Sixtythree percent of the students were of the opinion that self-medication is part of self-care. Most of the students read the expiration date on the drug label (88.6\%).

\section{Conclusion}

Acne is a highly prevalent condition among medical students and the practice of self-medication among acne sufferers is high. The practice of self-medication and visits to dermatologists were both significantly

Received 08/19/2019

Review began 08/19/2019 Review ended 08/21/2019 Published 08/28/2019

\section{() Copyright 2019}

Tameez-ud-din et al. This is an open

access article distributed under the terms of the Creative Commons Attribution License CC-BY 3.0., which permits unrestricted use, distribution, and reproduction in any medium, provided the original author and source are credited. more common in the students with lesions on the face. The knowledge of students regarding selfmedication of acne was not adequate.

Categories: Dermatology, Internal Medicine, Public Health

Keywords: acne, self-medication, medical students

\section{Introduction}

Acne is one of the most common skin conditions affecting teenagers of both sexes worldwide [1]. It is an inflammatory condition that results from an underlying pathology involving sebaceous glands of the skin. There are different morphological types of pimples or acne such as whiteheads, blackheads, cysts, nodules, and pustules [2]. Untreated acne may lead to scarring. The face is one of the most common sites for acne lesions, which results in considerable distress to the patient, usually out of proportion to the disease severity. The psychological and social impacts of acne have been the driving forces behind intensive efforts to find a suitable cure even for mild cases [3].

Self-medication is defined by the World Health Organization (WHO) as the "use of medicinal products by the consumer to treat self-recognized disorders or symptoms or the intermittent or continued use of medication prescribed by a physician for chronic or recurring diseases or symptoms." Self-medication is a fairly common practice among medical students due to a variety of factors such as ease of availability, exposure of medical settings, and pharmacological knowledge [4]. Even though the WHO advocates self-medication for the treatment of minor ailments, it does caution against its pitfalls such as adverse side effects and the emerging resistance among pathogens [5]. 


\section{Cureus}

The aim of this study was to aid the decision-makers in incorporating basic dermatological knowledge in the medical curriculum to avoid risky self-medication behaviors and to improve the clinical acumen of future doctors. The objectives of this study were to find the prevalence of acne vulgaris in medical students of Rawalpindi Medical University and to assess the knowledge, attitude, and practices regarding selfmedication for acne vulgaris in medical students.

\section{Materials And Methods}

This descriptive cross-sectional study was conducted at Rawalpindi Medical University, Rawalpindi, Pakistan, from January 2019 to June 2019. Students of all the medical years studying in our university were included in the study. Data were collected by using the convenient sampling technique. Students were asked to fill a semi-structured questionnaire. Incompletely filled questionnaires were excluded from the final results. Most of the questions were taken from a study by Karamata et al. [6]. The questionnaire had two parts, the first consisted of a demographic portion and questions about the site of acne, the pattern of selfmedication, and the source of information. The second part of the questionnaire comprised questions regarding knowledge, attitude, and practices of self-medication. Knowledge was assessed by six questions, including knowledge about dose, mechanism of action, precautions for use, complications, side effects, and contraindications of the drugs being used. The sections of attitude and practices had four and three questions, respectively. The results were reported as frequencies and percentages. Data were entered and analyzed using the Statistical Package for Social Sciences (SPSS) version 23.0 (IBM Corp, Armonk, US). Chisquare tests were applied for qualitative variables. A p-value of less than 0.05 was considered significant.

\section{Results}

Out of 349 students, 104 (29.8\%) were males, and 245 (70.2\%) were females. The mean age of the students was $21.2 \pm 1.9$ years. Seventy-two (20.6\%) students were from the first year, 40 (11.5\%) were from the second year, 52 (14.9\%) were from the third year, 62 (17.8\%) were from the fourth year, and 112 (32.1\%) students belonged to the final year. The medical year was not reported by 11 (3.2\%) participants.

The prevalence of acne among medical students was $69.9 \%(n=244)$. The sites of acne lesions are shown in Table 1 . Six (2.5\%) students did not mention the site of acne lesions.

\begin{tabular}{|l|l|}
\hline Region & Frequency (\%) \\
\hline Face & $168(68.9 \%)$ \\
\hline Face and back & $36(14.8 \%)$ \\
\hline Face, chest, and back & $20(8.2 \%)$ \\
\hline Back & $8(3.3 \%)$ \\
\hline Face and chest & $4(1.6 \%)$ \\
\hline Chest & $1(0.4 \%)$ \\
\hline Chest and back & $1(0.4 \%)$ \\
\hline
\end{tabular}

TABLE 1: Sites of acne lesions

Out of 244 students suffering from acne, 123 (50.4\%) practiced self-medication. The practice of selfmedication was significantly higher in students having acne lesions on the face (52.2\%), whereas only $10 \%$ of students with acne involving sites other than the face practiced self-medication $(\mathrm{p}=0.009)$. Dermatologist's consultation was sought by 134 (54.9\%) students suffering from acne. Students with acne lesions involving the face consulted a dermatologist significantly more often (57.7\%) than those with lesions on sites other than the face $(20 \%, \mathrm{p}=0.019)$. Seventy-three $(29.9 \%)$ students suffering from acne had a doctor in the family. Three (1.2\%) students did not respond to this question. Self-medication was significantly more frequent in students with a doctor in the family $(61.6 \%, \mathrm{p}=0.03)$.

Out of the 123 students who practiced self-medication, eight (6.5\%) used only oral medications while solely topical drugs were applied by 73 (59.3\%) students. Both oral and topical medications were used by 38 (30.9\%) students. Four (3.3\%) students did not mention the mode of drug administration.

Allopathy was the most common type of medication used by students ( $\mathrm{n}=75,47.8 \%$ ), followed by homemade remedies $(\mathrm{n}=52,33.1 \%)$. This is shown in Table 2 . 


\section{Cureus}

Type of medication

Allopathy

Home-made remedies

Homeopathy

Ayurvedic medication

Others (cosmetic products, chemical peels)
Frequency (\%)

$75(47.8 \%)$

$52(33.1 \%)$

$14(8.9 \%)$

$7(4.4 \%)$

$9(5.7 \%)$

\section{TABLE 2: Type of medication}

The most common reason for self-medication was the mild nature of the disease $(n=49,34.3 \%)$, followed by the easy availability of the drugs $(n=43,30.1 \%)$. This is shown in Table 3 .

\begin{tabular}{|l|l|}
\hline Reason for self-medication & Frequency (\%) \\
\hline Mildness of disease & $49(34.3 \%)$ \\
\hline Easy availability & $43(30.1 \%)$ \\
\hline Know treatment from the previous prescription & $20(14 \%)$ \\
\hline Lack of time & $16(11.2 \%)$ \\
\hline Pharmacological knowledge & $8(5.6 \%)$ \\
\hline Did not want to involve faculty & $5(3.5 \%)$ \\
\hline The embarrassment of discussing symptoms & $2(1.4 \%)$ \\
\hline
\end{tabular}

\section{TABLE 3: Reason for self-medication}

Acquaintances were the main source of information for most of the students ( $n=77,55.8 \%$ ), followed by the prescription issued to others $(\mathrm{n}=20,14.5 \%)$. This is shown in Table 4 .

\begin{tabular}{|l|c|}
\hline Source of information & Frequency (\%) \\
\hline Acquaintances & $77(55.8 \%)$ \\
\hline Prescription issued to others & $20(14.5 \%)$ \\
Self-decision & $13(9.4 \%)$ \\
Drug ads & $6(4.3 \%)$ \\
Books & $6(4.3 \%)$ \\
Others (Internet, seminars, lectures) & $16(11.6 \%)$
\end{tabular}

TABLE 4: Source of information

Most of the students knew the dose of the drug they were using ( $n=57,46.3 \%)$. Only 27 (22\%) of the students knew about the contraindications of the drugs, as shown in Table 5. Three (2.4\%) participants did not answer the knowledge section of the questionnaire. 


\section{Cureus}

\begin{tabular}{|c|c|c|}
\hline Knowledge & Yes n (\%) & No $n(\%)$ \\
\hline Dose of drug & $57(46.3 \%)$ & 63 (51.2\%) \\
\hline Mechanism of action & $39(31.7 \%)$ & $81(65.9 \%)$ \\
\hline Adverse effects & $38(30.9 \%)$ & $82(66.7 \%)$ \\
\hline Precautions for use & $51(41.5 \%)$ & $69(56.1 \%)$ \\
\hline Complications & $36(29.3 \%)$ & $83(67.5 \%)$ \\
\hline Contraindications & $27(22 \%)$ & $93(75.6 \%)$ \\
\hline
\end{tabular}

TABLE 5: Knowledge of self-medication

Eighty (65\%) students felt that their condition improved after self-medication while four (3.3\%) thought that the acne lesions worsened with the self-administration of drugs. Thirty-three students (26.8\%) felt that self-medication did not affect the outcome of their acne lesions. Six (4.9\%) students did not give a satisfactory answer to this question. The attitude of students towards self-medication is shown in Table 6. One $(0.8 \%)$ student did not answer the first three questions while two (1.6\%) students did not respond to the last question shown in the following table.

\begin{tabular}{|l|l|}
\hline Attitude & Yes n (\%) \\
\hline Self-medication is part of self-care & $77(62.6 \%)$ \\
\hline Advise self-medication to friends/family & $61(49.6 \%)$ \\
\hline Is dermatologist's consultation important for acne? & $110(89.4 \%)$ \\
\hline Is follow-up for acne important? & $111(90.2 \%)$ \\
\hline
\end{tabular}

TABLE 6: Attitude towards self-medication

The practices of medical students regarding self-medication are shown in Table 7 . One (0.8\%) student did not respond to the first question while two (1.6\%) students did not answer the last two questions as shown in Table 7.

\begin{tabular}{|l|l|}
\hline Practice & Yes n (\%) \\
\hline Do you read instructions on the drug label? & $88(71.5 \%)$ \\
\hline Do you read the expiration date of the drug? & $109(88.6 \%)$ \\
\hline Is the medication always available at home/hostel? & $54(27.6 \%)$ \\
\hline
\end{tabular}

TABLE 7: Practices regarding self-medication

\section{Discussion}

Acne is a very common skin condition affecting teenagers and adolescents worldwide. The prevalence of acne in our setup was found to be $69.9 \%$, which was consistent with the findings of Talanikar et al. [7]. Comparably, a study conducted in Karachi showed a prevalence of $55.9 \%$ among the students [8]. Selfmedication for acne is a fairly common practice among medical students. According to our findings, $50.4 \%$ of the students suffering from acne practiced self-medication, which was on par with the findings of Corey et al. [9]. Similarly, Karamata et al. reported self-medication in $59.2 \%$ of acne sufferers which was close to our findings [6]. According to Raiker et al., a higher number of medical students (77.4\%) practiced selfmedication [1]. 
The face was the most commonly involved site of acne in our study, with $68.9 \%$ of lesions involving this area of the body. Alanazi et al. also reported the presence of acne lesions on the face in the majority of secondary school students [10]. The practice of self-medication was significantly more common in students having lesions on the face. Moreover, students with facial lesions also seek dermatologist's consultation much more frequently than those with lesions on other body parts. The face is one of the most important parts of the human body from a cosmetic point of view and any visible lesion causes considerable distress to the patient. Further studies are required to clarify the relationship between the practice of self-medication and the site of acne lesions to improve the existing strategies for acne management. Similar comparisons have been made between gender and self-medication in some studies $[6,11]$.

The most common reason for self-medication in our study was the mildness of the condition (34.3\%), followed closely by easy availability (30.1\%). The mild nature of the disease has been reported as the most common reason in many studies [6-7]. Acquaintances (seniors/friends/members of the family) were the most frequently cited source of information in our study (55.8\%). Friends/seniors were also reported as the most common information source by Patil et al. [12]. The medical school curriculum is designed to give the students a thorough experience of the clinical settings, which results in a special bond of trust and friendship between batch mates and their seniors. For this reason, seniors and friends may influence medical students the most in their decision of self-medication.

Sixty-three percent of students in our study were of the opinion that self-medication is a component of selfcare, which was close to the findings of Karamata et al. [6]. Around 50\% of the students had no reservations about recommending the medication to their friends and family, similar to the results of Raikar et al. [1]. According to our findings, $89.4 \%$ of the students thought that the dermatologist's consultation was important for the treatment of acne. A study by Zafar et al. also reported similar findings [13]. The knowledge of the pharmacological properties and the effects of drugs used was less than 50\%, which is alarmingly low as a lack of adequate knowledge may lead to severe and undesirable side-effects. Most of the students in our study used allopathic medication (47.8\%) while homemade preparations were used by $33.1 \%$ of students. This was consistent with the findings of Kumar et al. [14]. The topical route of administration was most common in our study. Topical drugs were also the most commonly used drugs according to the findings of Karamata et al. [6]. The topical route is considered one of the safest routes of administration and the availability of a large number of over-the-counter topical drugs may make it a convenient choice for medical students.

The majority of the students in our study read the instructions and the expiration date on the drug label. While this is an encouraging statistic and reflects the cautious mindset of medical students regarding the use of medications, it does not address the problem of overuse of certain drugs, which may result in dangerous side-effects like drug resistance [15]. Self-medication is an emerging trend among medical students and effective measures are needed to curb the dangerous side-effects of self-medication.

There were some limitations to our study. Poor knowledge about the clinical definition of acne might have resulted in a slightly less than expected prevalence of acne and its self-medication. Some of the questionnaires had to be discarded due to inadequate responses.

\section{Conclusions}

Acne is a highly prevalent condition among the medical students and the practice of self-medication among acne sufferers is high. The mildness of disease was the most commonly cited reason for self-medication. The practice of self-medication and the visits to dermatologists were both more common in the students with lesions on the face. The knowledge and attitude of medical students regarding the self-medication of acne mandate improvement in the existing dermatology curriculum. Awareness of the properties, side-effects, and the appropriate dosing schedule of the drugs may help control the emerging epidemic of drug resistance.

\section{Additional Information \\ Disclosures}

Human subjects: Consent was obtained by all participants in this study. Ethical Review Board, Rawalpindi Medical University issued approval RSRS-2019-M-39. The above-mentioned study is within the ethical boundaries. There is no duplication of the above-mentioned study in this institution and the Board acknowledges the importance of this study. Animal subjects: All authors have confirmed that this study did not involve animal subjects or tissue. Conflicts of interest: In compliance with the ICMJE uniform disclosure form, all authors declare the following: Payment/services info: All authors have declared that no financial support was received from any organization for the submitted work. Financial relationships: All authors have declared that they have no financial relationships at present or within the previous three years with any organizations that might have an interest in the submitted work. Other relationships: All authors have declared that there are no other relationships or activities that could appear to have influenced the submitted work.

\section{Acknowledgements}


We would like to acknowledge the continuous support and guidance provided by Farooq Mohyud Din Chaudhary, Department of Gastroenterology, Nishtar Medical University \& Hospital, Multan, Pakistan. We would also like to thank Tameez-ud-din, Department of Dermatology, Rawalpindi Medical University, Rawalpindi, Pakistan.

\section{References}

1. Raikar DR, Manthale NS: A cross sectional study of self-medication for acne among undergraduate medical students. Int J Res Dermatol. 2018, 4:211-214. 10.18203/issn.2455-4529.IntJResDermatol20181821

2. Acne. (2019). Accessed: August 5, 2019: https://www.niams.nih.gov/health-topics/acne.

3. Uslu G, Şendur N, Uslu M, Şavk E, Karaman G, Eskin M: Acne: prevalence, perceptions and effects on psychological health among adolescents in Aydin, Turkey. J Eur Acad Dermatol Venereol. 2008, 22:462-469. 10.1111/j.1468-3083.2007.02497.x

4. WHO. Guidelines for the regulatory assessment of medicinal products for use in self-medication . (2000). Accessed: August 5, 2019:

https://apps.who.int/iris/bitstream/handle/10665/66154/WHO_EDM_QSM_00.1_eng.pdf? sequence $=1$ \&isAllowed $=$.

5. Report of the WHO expert committee on national drug policies . (1995). Accessed: August 5, 2019: https://apps.who.int/iris/bitstream/handle/10665/63068/WHO_DAP_95.9.pdf?sequence=1 \&isAllowed=y.

6. Karamata VV, Gandhi AM, Patel PP, Desai MK: Self-medication for acne among undergraduate medical students. Indian J Dermatol. 2017, 62:178-183. 10.4103/ijd.IJD_243_16

7. Talanikar H, Upadhye J: Knowledge, attitude and practices of medical students about self-medication for acne. Int J Res Med Sci. 2019, 7:849-853. 10.18203/2320-6012.ijrms20190935

8. Ali G, Mehtab K, Sheikh ZA, et al.: Beliefs and perceptions of acne among a sample of students from Sindh Medical College, Karachi. J Pak Med Assoc. 2010, 60:51-54.

9. Corey KC, Cheng CE, Irwin B, Kimball AB: Self-reported help-seeking behaviors and treatment choices of adolescents regarding acne. Pediatr Dermatol. 2013, 30:36-41. 10.1111/j.1525-1470.2012.01807.x

10. Alanazi MS, Hammad SM, Mohamed AE: Prevalence and psychological impact of acne vulgaris among female secondary school students in Arar city, Saudi Arabia, in 2018. Electron Physician. 2018, 10:7224-7229. $10.19082 / 7224$

11. Lukovic JA, Miletic V, Pekmezovic T, Trajkovic G, Ratkovic N, Aleksic D, Grgurevic A: Self-medication practices and risk factors for self-medication among medical students in Belgrade, Serbia. PLoS One. 2014, 11:114644. 10.1371/journal.pone.0114644

12. Patil SB, Vardhamane SH, Patil BV, Santoshkumar J, Binjawadgi AS, Kanaki AR: Self-medication practice and perceptions among undergraduate medical students: a cross-sectional study. J Clin Diagn Res. 2014, 8:20-23. 10.7860/JCDR/2014/10579.5313

13. Zafar SN, Syed R, Waqar S, et al.: Self-medication amongst university students of Karachi: prevalence, knowledge and attitudes. J Pak Med Assoc. 2008, 58:214-217.

14. Kumar N, Kanchan T, Unnikrishnan B, et al.: Perceptions and practices of self-medication among medical students in coastal South India. PLoS One. 2013, 28:72247. 10.1371/journal.pone.0072247

15. Amirthalingam S, Yi KS, Ching LT, Mun NY: Topical antibacterials and global challenges on resistance development. Trop J Pharm Res. 2015, 14:919-924. 10.4314/tjpr.v14i5.24 